\title{
Assessment of intake inadequacy and food sources of zinc of people in China
}

\author{
Guansheng $\mathrm{Ma}^{1,2, *}$, Yanping $\mathrm{Li}^{1,2}$, Ying Jin ${ }^{1}$, Songming Du ${ }^{1}$, Frans J Kok ${ }^{2}$ and \\ Xiaoguang Yang ${ }^{1}$ \\ ${ }^{1}$ National Institute for Nutrition and Food Safety, Chinese Center for Disease Control and Prevention, 29 Nan Wei \\ Road, Beijing 100050, People's Republic of China: ${ }^{2}$ Division of Human Nutrition, Wageningen University, \\ Wageningen, The Netherlands
}

Submitted 28 March 2006: Accepted 24 0ctober 2006: First published online 19 February 2007

\begin{abstract}
Objectives: To assess the intake inadequacy and food sources of zinc of people in China.

Design and subjects: Diets of 68962 subjects aged 2-101 years (urban 21 103, rural 47859) in the 2002 China National Nutrition and Health Survey were analysed. Dietary intake was assessed using 24-hour recall for three consecutive days. Zinc intake inadequacy was calculated based on values suggested by the World Health Organization.

Results: The median zinc intake ranged from $4.9 \mathrm{mg} \mathrm{day}^{-1}$ (urban girls, $2-3$ years) to $11.9 \mathrm{mg} \mathrm{day}^{-1}$ (rural males, $19+$ years). The zinc density of urban residents (2-3 to $19+$ years) was $5.0-5.3 \mathrm{mg} \mathrm{day}^{-1}(1000 \mathrm{kcal})^{-1}$, significantly higher than that of their rural counterparts $\left(4.7-4.8 \mathrm{mg} \mathrm{day}^{-1}(1000 \mathrm{kcal})^{-1}\right)$. Differences in food sources of zinc from cereal grains (27.4-45.1 vs. 51.6-63.2\%) and animal foods (28.4-54.8 vs. $16.8-30.6 \%)$ were found between urban and rural residents. Zinc from vegetables and fruits (8.2-13.8 vs. 9.7-12.4\%) and legumes (1.3-3.3 vs. 2.5-3.4\%) was comparable between urban and rural residents. The proportion of zinc intake inadequacy ranged between 2.8\% (urban females, 19+ years) and 29.4\% (rural lactating women). Rural residents had higher proportions of zinc intake inadequacy than their urban counterparts. Significantly higher proportions of zinc inadequacy were found in the category of phytate/zinc molar ratio $>15$ for both rural and urban residents.

Conclusions: About 20\% of rural children are at risk of inadequate zinc intake, with phytate as a potential important inhibitor. Moreover, lactating women are also considered a vulnerable group.
\end{abstract}

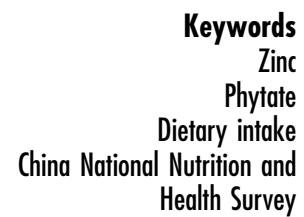

Zinc

Phytate Nutrition and Health Survey
Zinc is an essential mineral that performs biochemical functions important for maintaining human health ${ }^{1-6}$. Zinc deficiency may be widespread in developing countries but the true magnitude of mild and moderate zinc deficiency is unknown, in part because of the lack of a reliable and specific index of zinc status ${ }^{7,8}$. Use of the Recommended Dietary Allowance ${ }^{9}$ and Estimated Average Requirement ${ }^{10,11}$ is suggested for estimating the prevalence of nutrient inadequacy in population groups.

Zinc deficiency may arise from low dietary intake, low bioavailability and/or interaction with other nutrients, and losses through disease processes ${ }^{12-14}$. Inhibitors of zinc absorption are believed to be the more likely causative factor $^{15}$. Phytate, present in whole grains, cereals and legumes, is a strong inhibitor of zinc absorption. Phytate is high in plant-based diets, which is a major inhibitory factor for zinc absorption. The phytate/zinc molar ratio is used to predict the inhibitory effect of phytate on the bioavailability of zinc ${ }^{8,16,17}$. The World Health Organization (WHO) suggests that the assessment of dietary zinc status should take inhibitory factors into account, and phytate data must be available ${ }^{8}$. However, the inhibitory effect of phytate on the bioavailability of zinc has not been examined in China owing to a lack of information on the phytate content of foods in the China Food Composition Table ${ }^{18}$. In 2005, the phytate content of 60 food samples commonly consumed in China was analysed ${ }^{19}$ using an anion-exchange method, which made it possible to assess the dietary zinc intake of people in China taking the inhibitory effect of phytate into account. Thus the aims of the present study were to: (1) assess the prevalence of zinc intake inadequacy in relation to the effect of phytate in Chinese diets; (2) examine if zinc intake inadequacy differs by age, sex and region in China; and (3) describe the food sources of zinc in Chinese diets. 


\section{Subjects and methods}

\section{Sampling}

The 2002 China National Nutrition and Health Survey (CNNHS) is a nationally representative cross-sectional survey that covered 31 provinces, autonomous regions and the municipalities directly affiliated with the Central Government (Hong Kong, Macao and Taiwan were not included). A multi-stage cluster sampling method was used for subject selection. In stage 1, all 2860 counties/districts/cities of China were divided into six categories (big cities, medium and small cities, rural 1, 2, 3 and 4) based on type and level of economic development (from high to low). Twenty-two counties/districts/cities were randomly selected from each category, thus a total of 132 counties/districts/cities were randomly selected at this stage. In stage 2 , three townships/sub-districts were randomly selected from each of the selected counties/districts/cities, resulting in 396 townships/sub-districts being randomly selected at this stage. In stage 3, two villages/neighbourhood committees were randomly selected from the selected townships/sub-districts, giving a total of 792 villages/neighbourhood committees. In stage 4, 90 households were randomly selected from each selected village/neighbourhood, which resulted in a final total of 71971 households that were randomly selected to represent the national data.

\section{Dietary intake assessment}

The dietary survey was conducted among all members of 30 households that were randomly selected from the preselected 90 households. All family members above 2 years old from the selected households were invited for the dietary intake assessment. A total of 23470 from 71971 households participated in the dietary intake assessment ${ }^{20}$.

The protocol of the survey was approved by the Ethical Committee of the National Institute for Nutrition and Food Safety, Chinese Center for Disease Control and Prevention. A signed consent form was obtained from each subject or his/her parent or guardian.

Information on food intake was collected using the 24hour dietary recall method for three consecutive days (two weekdays and one weekend day) by trained interviewers. The parent or guardian was interviewed for children aged 2-16 years.

Zinc intake was calculated using the data of dietary recall in conjunction with the China Food Composition Table $^{18}$. The composition of infant formula is available in the tables and was included in the calculation. Zinc content of foods in the China Food Composition Table was determined by atomic absorption spectrophotometry ${ }^{18}$. Duplicate food samples were analysed. Standard reference materials were obtained from the China National Center of Standard Material for quality control. The relative standard deviation was within 10\%.
Sixty food samples, including rice, wheat flour, corn and soybean products commonly consumed in China, were selected based on the frequency of foods consumed in the 2002 CNNHS $^{19}$. The phytate content of these food samples was determined using an anionexchange method ${ }^{21}$. Phytate intake was calculated using the phytate content in conjunction with the dietary recall data. The average daily dietary intakes of zinc and phytate were calculated using the mean value of the three days' intakes.

The contributions of individual foods to zinc were calculated by summing the amount of zinc consumed from each food by all subjects in each age group and dividing by the total intake from all foods for all subjects in the respective age group.

Phytate/zinc molar ratio was calculated as the phytate intake per day in mmol divided by the zinc intake per day in mmol. The proportions of subjects with different phytate/zinc molar ratios $(<5,5-15,>15)$ were calculated. The percentage of people with zinc intake below the WHO normative requirement ${ }^{8}$ at different phytate/zinc molar ratios was calculated. The average individual normative requirements for zinc from the diet are developed according to zinc availability, the three (high, moderate and low) bioavailability levels corresponding to $50 \%, 30 \%$ and $15 \%$ absorption ${ }^{8}$. The normative requirements of the first trimester for pregnant women, and of first three months for lactating women, were used to assess the inadequacy of zinc intake for these groups.

\section{Statistical analysis}

Values of dietary zinc intake are expressed as median and interquartile range. Zinc intake is expressed as $\mathrm{mg} \mathrm{day}^{-1}$ and zinc density as $\mathrm{mgday}^{-1}(1000 \mathrm{kcal})^{-1}$. Normal probability plots and Kolmogorov-Smirnov tests were used to determine whether variables followed a normal distribution. To analyse the associations of sex, age, region and their interactions with dietary zinc intake, a general linear model factorial analysis was applied with Tukey's post hoc comparisons. The results are presented by sex, age and region for the significant interactions found between sex and age, and between age and region. Differences in zinc intake of subjects by sex and region were compared using Wilcoxon's signed rank sum test. The proportion of subjects with different phytate/zinc molar ratios was calculated, while the proportion of zinc intakes less than the WHO suggested normative requirement ${ }^{8}$ was calculated by region and phytate/zinc molar ratio. Differences in the abovementioned proportions between urban and rural areas were compared using the $\chi^{2}$ test. All statistical analyses were conducted with the SAS Statistical Package (8.2e for Windows; SAS Institute Inc.). Statistical significance was set at 0.05 . 


\section{Results}

\section{Characteristics of the study population}

A total of 68962 subjects were included in the present analysis. Of these, 21103 (males 10027 , females 11076) were from urban areas, while 47859 (males 23524, females 24335) were from rural areas. There were 310 pregnant women and 470 lactating women. The means of body mass index and dietary energy intake are presented by age group and region in Table 1 .

\section{Dietary zinc intake of people in China}

The median zinc intakes by age, sex and region are presented in Table 2 . There were significant effects of age $(F(6, \quad 68956)=372.8 ; \quad P<0.001)$ and sex $(F(1$, $68961)=113.8 ; \quad P<0.001)$, and first-level interactions between region and age $(F(6,68956)=22.5 ; P<0.001)$ and between age and $\operatorname{sex}(F(6,68956)=15.5 ; P<0.001)$, for dietary zinc intakes. Median zinc intake ranged from $4.9 \mathrm{mg} \mathrm{day}^{-1}$ (urban girls, $2-3$ years) to $11.9 \mathrm{mg} \mathrm{day}^{-1}$ (rural males, $19+$ years). The zinc intake of urban boys aged 2-3 years was higher than that of their rural counterparts (6.2 vs. $5.1 \mathrm{mg} \mathrm{day}^{-1}$ ). In contrast, the zinc intake of rural adults (19+ years) was significantly higher than that of their urban counterparts (males 11.9 vs. $10.5 \mathrm{mg} \mathrm{day}^{-1}$; females 10.2 vs. $8.9 \mathrm{mg} \mathrm{day}^{-1}$ ). The younger the age group, the less the zinc intake. Rural lactating women consumed more zinc than their urban counterparts (11.0 vs. $9.8 \mathrm{mg} \mathrm{day}^{-1}$ ) whereas urban pregnant women consumed comparable amounts of zinc to their rural counterparts (10.7 vs. $\left.10.9 \mathrm{mg} \mathrm{day}^{-1}\right)$.

There were significant effects of age $(F(6,68956)=4.9$; $P<0.001)$ and region $(F(1,68961)=278.8 ; P<0.001)$, first-level interactions between region and age $(F(6$, $68956)=4.2 ; P<0.001)$ and between age and sex $(F(6$, $68956)=3.3 ; \quad P<0.001)$, as well as second-level interactions between sex, region and age $(F(4$, 68958) $=3.9 ; P<0.001$ ) for dietary zinc density. The median zinc density of all age groups was between 4.7 and $5.7 \mathrm{mg} \mathrm{day}^{-1}\left(1000 \mathrm{kcal}^{-1}\right.$ (Table 2 ). The zinc density of urban residents $(2-3$ to $19+$ years $)$ was $5.0-$ $5.3 \mathrm{mg} \mathrm{day}^{-1}\left(1000 \mathrm{kcal}^{-1}\right.$, significantly higher than that of their rural counterparts $\left(4.7-4.8 \mathrm{mg} \mathrm{day}^{-1}\right.$ (1000 $\mathrm{kcal}^{-1}$ ). No significant difference was found between different age groups. Variation in median zinc intake was found between males and females within the same region and age group. Zinc density of the diets of urban boys (23 years) was higher than that of their female counterparts; in contrast, the rural boys (2-3 years) and rural adults consumed diets of lower zinc density than their female counterparts. Urban pregnant women had higher dietary zinc density than their rural counterparts (5.7 vs. $4.7 \mathrm{mg} \mathrm{day}^{-1}\left(1000 \mathrm{kcal}^{-1}\right)$. No difference in zinc density was found between urban and rural lactating women.

\section{Food sources of zinc}

Cereal grains including rice, wheat flour and its products contributed $27.4-63.2 \%$ to dietary zinc intake, while $16.8-$ $54.8 \%$ zinc came from animal foods. Vegetables and fruits provided $8.2-13.8 \%$ of dietary zinc, while legumes contributed only $1.3-3.4 \%$ of dietary zinc. Large discrepancies were found in the food sources of zinc from staple and animal foods between urban and rural residents within the same age group. Staple foods provided 27.4$45.1 \%$ zinc for urban residents, 51.6-63.2\% for rural residents. Animal foods contributed $28.4-54.8 \%$ of dietary zinc for urban residents, much higher than that for their respective rural counterparts (16.8-30.6\%). Vegetables, fruits and legumes provided comparable zinc for both urban and rural residents. Detailed information on the food sources of dietary zinc intake stratified by age, sex and region is shown in Table 3.

Table 1 Characteristics of the study population

\begin{tabular}{|c|c|c|c|c|c|c|c|c|c|c|}
\hline \multirow[b]{3}{*}{ Group } & \multicolumn{5}{|c|}{ Urban } & \multicolumn{5}{|c|}{ Rural } \\
\hline & \multirow[b]{2}{*}{$n$} & \multicolumn{2}{|c|}{$\begin{array}{c}\mathrm{BMl} \\
\left(\mathrm{kg} \mathrm{m}^{-2}\right)\end{array}$} & \multicolumn{2}{|c|}{$\begin{array}{c}\text { Energy } \\
\left(\mathrm{kcal} \mathrm{day}^{-1}\right)\end{array}$} & \multirow[b]{2}{*}{$n$} & \multicolumn{2}{|c|}{$\begin{array}{c}\mathrm{BMl} \\
\left(\mathrm{kg} \mathrm{m}^{-2}\right)\end{array}$} & \multicolumn{2}{|c|}{$\begin{array}{c}\text { Energy } \\
\left(\mathrm{kcal} \mathrm{day}^{-1}\right)\end{array}$} \\
\hline & & Mean & SD & Mean & SD & & Mean & SD & Mean & SD \\
\hline \multicolumn{11}{|l|}{ Males } \\
\hline $2-3$ years & 154 & 16.2 & 1.8 & 1386.8 & 1006.7 & 623 & 16.2 & 1.7 & 1212.8 & 613.4 \\
\hline $4-8$ years & 455 & 15.9 & 2.3 & 1528.3 & 694.6 & 2049 & 15.2 & 1.5 & 1589.7 & 585.9 \\
\hline $9-13$ years & 641 & 17.4 & 2.9 & 1858.0 & 711.9 & 2641 & 16.5 & 2.4 & 2007.1 & 652.4 \\
\hline $14-18$ years & 554 & 19.7 & 3.1 & 2196.0 & 808.5 & 1461 & 18.8 & 2.5 & 2414.2 & 700.2 \\
\hline $19+$ years & 8223 & 24.0 & 3.5 & 2129.9 & 790.0 & 16750 & 22.4 & 3.2 & 2600.2 & 750.1 \\
\hline \multicolumn{11}{|l|}{ Females } \\
\hline $2-3$ years & 108 & 15.7 & 1.4 & 1439.0 & 2510.9 & 466 & 15.6 & 1.5 & 1160.7 & 537.7 \\
\hline $4-8$ years & 436 & 15.3 & 2.0 & 1392.8 & 557.0 & 1758 & 14.8 & 1.4 & 1512.6 & 618.4 \\
\hline $9-13$ years & 598 & 17.0 & 2.9 & 1700.1 & 645.2 & 2351 & 16.4 & 2.4 & 1830.0 & 571.6 \\
\hline $14-18$ years & 484 & 20.3 & 3.0 & 1816.0 & 656.3 & 1259 & 19.8 & 2.5 & 2076.9 & 694.1 \\
\hline $19+$ years & 9340 & 23.9 & 3.8 & 1808.0 & 749.2 & 17831 & 22.9 & 3.5 & 2238.6 & 678.1 \\
\hline Pregnant & 55 & 22.5 & 3.2 & 1938.7 & 603.3 & 255 & 24.2 & 3.5 & 2380.7 & 714.4 \\
\hline Lactating & 55 & 22.3 & 2.0 & 1979.1 & 635.6 & 415 & 23.2 & 4.4 & 2421.6 & 742.7 \\
\hline
\end{tabular}

BMI - body mass index; SD - standard deviation. 
Table 2 Median (P50) and interquartile range (P25, P75) of zinc intake and zinc density by age, sex and region

\begin{tabular}{|c|c|c|c|c|c|c|c|c|c|c|c|c|}
\hline \multirow[b]{3}{*}{ Group } & \multicolumn{6}{|c|}{ Zinc intake $\left(\mathrm{mg} \mathrm{day}^{-1}\right)$} & \multicolumn{6}{|c|}{ Zinc density $\left(\mathrm{mg} \mathrm{day}^{-1}(1000 \mathrm{kcal})^{-1}\right)$} \\
\hline & \multicolumn{3}{|c|}{ Urban } & \multicolumn{3}{|c|}{ Rural } & \multicolumn{3}{|c|}{ Urban } & \multicolumn{3}{|c|}{ Rural } \\
\hline & P25 & P50 & P75 & P25 & P50 & P75 & P25 & P50 & P75 & P25 & P50 & P75 \\
\hline \multicolumn{13}{|l|}{ Males } \\
\hline $2-3$ years & 4.7 & $6.2^{\mathrm{c}}$ & 7.9 & 3.9 & $5.1^{\star, \mathrm{e}}$ & 6.9 & 4.5 & 5.3 & 6.4 & 4.1 & $4.7^{\star}$ & 5.4 \\
\hline $4-8$ years & 5.2 & $7.1^{\mathrm{c}}$ & 9.3 & 5.5 & $7.1^{d}$ & 9.0 & 4.3 & 5.0 & 6.0 & 4.2 & $4.7^{*}$ & 5.3 \\
\hline $9-13$ years & 6.9 & $9.1^{\mathrm{b}}$ & 12.1 & 7.3 & $9.0^{\mathrm{C}}$ & 11.2 & 4.4 & 5.0 & 6.3 & 4.3 & $4.7^{\star}$ & 5.2 \\
\hline $14-18$ years & 8.4 & $10.7^{\mathrm{a}}$ & 13.8 & 8.9 & $11.0^{\mathrm{b}}$ & 13.6 & 4.3 & 5.1 & 6.0 & 4.3 & $4.7^{*}$ & 5.2 \\
\hline $19+$ years & 8.1 & $10.5^{\mathrm{a}}$ & 13.6 & 9.7 & $11.9^{\star, a}$ & 14.4 & 4.4 & 5.1 & 6.1 & 4.3 & $4.7^{*}$ & 5.2 \\
\hline \multicolumn{13}{|l|}{ Females } \\
\hline $2-3$ years & 3.7 & $4.99^{+}, \mathrm{cd}$ & 7.2 & 3.7 & $5.1^{\mathrm{a}}$ & 7.0 & 4.2 & $5.1 \dagger$ & 6.1 & 4.2 & $4.8 \dagger$ & 5.5 \\
\hline $4-8$ years & 5.1 & $6.7^{\mathrm{c}}$ & 8.9 & 5.2 & $6.8 \dagger^{, b}$ & 8.6 & 4.4 & 5.1 & 6.1 & 4.2 & 4.7 & 5.3 \\
\hline $9-13$ years & 6.3 & $8.2 \dagger^{\mathrm{ad}}$ & 10.9 & 6.7 & $8.3+^{, c}$ & 10.3 & 4.4 & 5.1 & 6.0 & 4.3 & $4.8^{*}$ & 5.3 \\
\hline $14-18$ years & 7.0 & $8.9 \dagger^{\mathrm{ab}}$ & 11.8 & 7.6 & $9.3 \dagger^{, d}$ & 11.8 & 4.4 & 5.1 & 6.3 & 4.3 & $4.8^{\star}$ & 5.2 \\
\hline $19+$ years & 6.9 & $8.9 \dagger, \mathrm{b}$ & 11.6 & 8.3 & $10.2^{*}+$,e & 12.5 & 4.4 & 5.2 & 6.2 & 4.3 & $4.8^{*} \dagger$ & 5.3 \\
\hline Pregnant & 8.1 & $10.7^{\mathrm{ab}}$ & 14.1 & 8.9 & $10.9^{\text {ef }}$ & 13.6 & 4.5 & 5.7 & 6.6 & 4.2 & $4.7^{\star}$ & 5.3 \\
\hline Lactating & 7.1 & $9.8^{\mathrm{abcd}}$ & 11.9 & 9.0 & $11.0^{\star, f g}$ & 13.3 & 4.2 & 4.9 & 5.9 & 4.3 & 4.8 & 5.3 \\
\hline
\end{tabular}

A general linear model was performed with Tukey post hoc analysis to compare the effects of age (by sex and by region). Values not sharing the same superscript letter $(\mathrm{a}-\mathrm{g})$ denote a significant difference between age groups of the same sex, $P<0.05$.

* Significant difference between urban and rural residents within the same age and sex group, Wilcoxon's signed rank sum test: $P<0.05$.

† Sex difference within the same age and region, Wilcoxon's signed rank sum test: $P<0.05$.

\section{Proportions of subjects with different phytate/zinc molar ratios}

Variations in the proportion of subjects with the same phytate/zinc molar ratio were found between the different age and/or sex subgroups (Table 4). Some $28.6-46.8 \%$ of urban residents and $3.9-8.0 \%$ of rural residents had phytate/zinc molar ratio $<5$, while $48.7-$ $65.7 \%$ of residents had phytate/zinc molar ratio between 5 and 15 , and $4.5-18.2 \%$ of urban residents and $27.8-$ $36.4 \%$ of rural residents had phytate/zinc molar ratio $>15$. The proportion of rural residents with phytate/zinc molar ratio $>15$ was significantly higher than that of their urban counterparts. A significant effect of age on the proportion of subjects with different phytate/zinc molar ratios was found in all subgroups. Significant sex difference was only found in rural children aged 9-13 years (Table 4).

\section{Prevalence of zinc intake inadequacy}

Table 5 presents the prevalence of zinc intake inadequacy by age, sex and region. The proportion of zinc intake inadequacy ranged between 2.8\% (urban females, $19+$ years) and $29.4 \%$ (rural lactating women). The distribution was much higher when phytate/zinc molar ratio $>15$ was considered: $10.3 \%$ for rural females, $19+$ years and $100 \%$ for urban lactating women. The proportion of zinc intake inadequacy among urban residents was $2.8-16.4 \%$, significantly lower than that of their rural counterparts (3.6-29.4\%). Prevalence of zinc intake inadequacy was significantly higher among male adults (19+ years) than their female counterparts. The zinc intake of $5.5 \%$ of pregnant women and $29.4 \%$ of lactating women was inadequate.

\section{Discussion}

Information on zinc intake in developing countries is limited because of the paucity of data on the zinc content of local staple foods ${ }^{22}$. China developed food composition tables in the 1960s and keeps them updated using reliable and valid determination methods ${ }^{18}$. The composition of fortified foods is also available in the China Food Composition Table. The strength of the present study is the use of three days of 24-hour dietary recall data of a national representative sample population in conjunction with the China Food Composition Table. One limitation of this study is that the zinc from dietary supplements was not taken into account. As the use of dietary supplements in China $^{23}$ is low (urban 10.3\%, rural 2.9\%) compared with that $(39.5 \%)$ in the USA ${ }^{9}$, we assumed that zinc intake was underestimated to a small extent. This limitation suggests that the use of dietary supplements and their contribution to total nutrient intake in the Chinese population, especially for urban persons, should be monitored in future surveys.

The present study found that the zinc intake of people in China is lower than that of the US population ${ }^{9,24,25}$, but comparable to that in the $\mathrm{UK}^{26,27}$, Germany ${ }^{28}$ and New Zealand $^{29}$. People in China consume more zinc than their counterparts in Chile ${ }^{30}$, India ${ }^{31}$ and Korea ${ }^{32}$. However, the adequacy of zinc intake depends not only on the amount, but also its bioavailability. The inhibitory factors that may interact with zinc should be examined when assessing the dietary intake of zinc ${ }^{8,33}$. People consuming a diet that provides marginal zinc intake may not absorb an adequate amount of zinc if they are also consuming foods high in phytate. The average phytate intake of people in China $\left(1186 \mathrm{mg} \mathrm{day}^{-1}\right)^{34}$ is higher than that in Western 


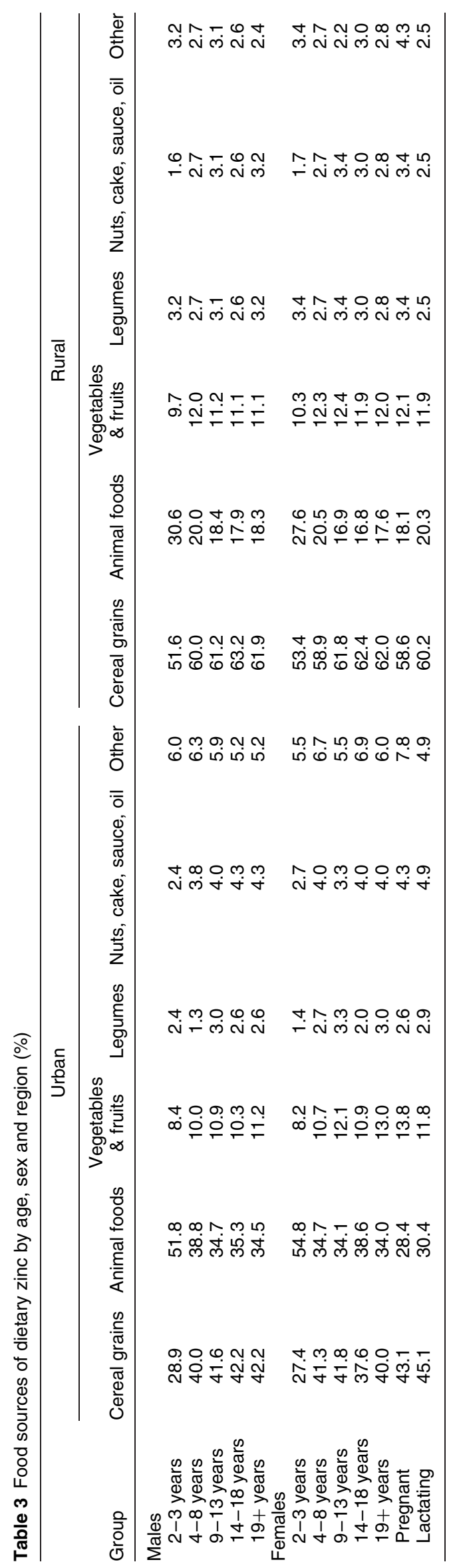

Table 4 Proportion of subjects with different phytate/zinc molar ratio (\%)

\begin{tabular}{|c|c|c|c|c|c|c|}
\hline \multirow[b]{3}{*}{ Group } & \multicolumn{3}{|c|}{ Urban } & \multicolumn{3}{|c|}{ Rural } \\
\hline & \multicolumn{3}{|c|}{$\begin{array}{l}\text { Phytate/zinc molar } \\
\text { ratio }\end{array}$} & \multicolumn{3}{|c|}{$\begin{array}{l}\text { Phytate/zinc molar } \\
\text { ratio* }\end{array}$} \\
\hline & $<5$ & $5-15$ & $>15$ & $<5$ & $5-15$ & $>15$ \\
\hline \multicolumn{7}{|l|}{ Males } \\
\hline $2-3$ years & 46.8 & 48.7 & 4.5 & 8.0 & 64.2 & $27.8^{*}$ \\
\hline $4-8$ years & 28.6 & 62.9 & 8.6 & 5.0 & 65.2 & $29.9^{*}$ \\
\hline $9-13$ years & 32.6 & 58.8 & 8.6 & 5.6 & 61.8 & $32.5^{\star}$ \\
\hline $14-18$ years & 32.1 & 59.7 & 8.1 & 4.8 & 61.7 & $33.5^{\star}$ \\
\hline $19+$ years & 32.4 & 60.6 & 7.0 & 5.2 & 61.7 & $33.1^{*}$ \\
\hline Age effect & \multicolumn{3}{|c|}{$\chi^{2}=21.6, P<0.01$} & \multicolumn{3}{|c|}{$\chi^{2}=25.3, P<0.01$} \\
\hline \multicolumn{7}{|l|}{ Females } \\
\hline $2-3$ years & 35.2 & 59.3 & 5.6 & 7.7 & 64.4 & $27.9^{\star}$ \\
\hline $4-8$ years & 30.3 & 59.6 & 10.1 & 5.7 & 65.7 & $28.6^{*}$ \\
\hline $9-13$ years & 33.1 & 57.5 & 9.4 & 3.9 & 63.1 & $33.0^{*} \dagger$ \\
\hline $14-18$ years & 34.1 & 59.9 & 6.0 & 5.8 & 59.5 & $34.7^{*}$ \\
\hline $19+$ years & 32.7 & 60.2 & 7.1 & 4.9 & 61.1 & $34.0^{*}$ \\
\hline Pregnant & 30.9 & 50.9 & 18.2 & 6.3 & 61.6 & $32.2^{*}$ \\
\hline Lactating & 29.1 & 63.6 & 7.3 & 5.1 & 58.6 & $36.4^{*}$ \\
\hline Age effect & \multicolumn{3}{|c|}{$\chi^{2}=22.0, P<0.05$} & \multicolumn{3}{|c|}{$\chi^{2}=45.4, P<0.01$} \\
\hline
\end{tabular}

* Significant difference between urban and rural residents, $\chi^{2}$ test: $P<0.05$.

† Sex difference within the same age and region, $\chi^{2}$ test: $P<0.05$.

countries $^{35,36}$ and less than that of Korean ${ }^{37}$ and Indian people $^{38}$. The proportion of people with inadequate zinc intake was considerably high in the phytate/zinc molar ratio $>15$ category, indicating that zinc in the diets of these populations would be affected by their high phytate intake. The vulnerable groups of zinc deficiency in China are children, adolescents and lactating women, especially those in rural areas. As zinc plays an important role in children's growth ${ }^{39}$ and during pregnancy ${ }^{40,41}$, zinc deficiency will impact severely on human health ${ }^{42}$, with adverse effects that include growth retardation, abnormal

Table 5 Proportion of zinc intakes less than the normative requirement of the World Health Organization (\%)

\begin{tabular}{|c|c|c|c|c|c|c|c|}
\hline \multirow[b]{3}{*}{ Group } & \multicolumn{4}{|c|}{ Urban } & \multicolumn{3}{|c|}{ Rural } \\
\hline & \multicolumn{4}{|c|}{ Phytate/zinc molar ratio } & \multicolumn{3}{|c|}{ Phytate/zinc molar ratio } \\
\hline & $<5$ & $5-15$ & $>15$ & Total & $<55-15$ & $>15$ & Total \\
\hline \multicolumn{8}{|l|}{ Males } \\
\hline $2-3$ years & 0.0 & 8.8 & 33.3 & 6.3 & 4.59 .1 & 69.5 & $25.8^{*}$ \\
\hline $4-8$ years & 0.9 & 9.0 & 69.7 & 11.9 & $0.01 .1^{*}$ & $46.1^{*}$ & 14.7 \\
\hline $9-13$ years & 0.0 & 7.3 & 55.3 & 8.9 & $0.00 .9^{*}$ & 49.3 & $16.8^{*}$ \\
\hline $14-18$ years & 2.8 & 6.3 & 67.6 & 10.2 & $1.91 .6^{*}$ & $47.4^{\star}$ & $17.2^{\star}$ \\
\hline $19+$ years & 0.2 & 2.8 & 43.6 & 4.8 & $0.40 .3^{*}$ & $19.4^{*}$ & $6.6^{*}$ \\
\hline \multicolumn{8}{|l|}{ Females } \\
\hline $2-3$ years & 2.9 & 5.9 & 80.0 & 8.8 & 3.26 .7 & 62.5 & $21.7^{*}$ \\
\hline $4-8$ years & 1.0 & $3.4 \dagger$ & 55.0 & 8.6 & $0.02 .6 \dagger$ & 46.5 & $15.1^{*}$ \\
\hline $9-13$ years & 0.0 & 6.0 & 51.0 & 8.3 & $0.01 .9^{*} \dagger$ & $42.5 \dagger$ & $15.6^{*}$ \\
\hline $14-18$ years & 0.7 & 5.1 & 50.0 & $5.9 \dagger$ & $1.62 .5^{*}$ & 49.7 & $18.8^{\star}$ \\
\hline $19+$ years & 0.1 & $1.3 \dagger$ & $27.8 \dagger$ & $2.8 \dagger$ & $0.10 .2^{*} \dagger$ & $10.3^{\star} \dagger$ & $3.6^{*} \dagger$ \\
\hline Pregnant & 0.0 & 0.0 & 40.0 & $7.3^{\circ}$ & 0.00 .0 & 17.1 & 5.5 \\
\hline Lactating & 0.0 & 14.3 & 100.0 & 16.4 & $0.02 .9^{*}$ & 76.2 & $29.4^{*}$ \\
\hline
\end{tabular}

* Significant difference between urban and rural residents, $\chi^{2}$ test: $P<0.05$.

† Sex difference within the same age and region, $\chi^{2}$ test: $P<0.05$. 
immune function, impaired cognitive function, increased maternal morbidity, prolonged gestation and increased risk to the foetus.

Information on the inadequacy of dietary zinc intakes should be interpreted together with data derived from other assessment methods. The national prevalence of stunting among children $<5$ years old can be used as an indirect indicator of a population's risk of zinc deficiency ${ }^{43,44}$. The national prevalence of stunting in China is $3.3-8.6 \%$ for urban children $<5$ years and $17.3-$ $20.9 \%$ for their rural counterparts ${ }^{45}$. It can be concluded that the level of risk for zinc deficiency is low for the urban population and moderate for the rural population in China. Further population assessment of zinc status by serum zinc concentrations in a representative sample of the population should be made in order to identify segments of the population at high risk. Appropriate intervention strategies including supplementation, food fortification, dietary diversification and biofortification should be developed to target different populations.

In conclusion, urban people in China are at low risk of zinc deficiency, whereas the rural population is at a moderate level of risk for zinc deficiency. Lactating women and rural children are vulnerable populations in China. Effective strategies correcting these problems should be developed and implemented in targeted risk groups.

\section{Acknowledgements}

Sources offunding: The 2002 China National Nutrition and Health Survey was funded by the Ministry of Health and Ministry of Science and Technology, China (2001DEA30035, 2003DIA6N008).

Conflict of interest declaration: There is no interest conflict.

Authorship responsibilities: G.M. was responsible for study design, project management, data analysis, manuscript writing and interpretation of results. Y.L. was responsible for data cleaning and analysis, manuscript writing and interpretation of results. Y.J. was responsible for determinig the phytate content of foods, manuscript writing and interpretation of results. S.D. was responsible for manuscript writing and interpretation of results. F.J.K. was responsible for manuscript writing and interpretation of results. X.Y. was responsible for study design, project management and interpretation of results.

Acknowledgements: We thank all team members and all participants from the 31 provinces. We are very appreciative of the support of UNICEF, WHO, Unilever China and the Danone Nutrition Institute China.

\section{References}

1 Abdel-Mageed AB, Oehme FW. A review of the biochemical roles, toxicity and interactions of zinc, copper and iron: I. zinc. Veterinary and Human Toxicology 1990; 32: 34-9.
2 Black RE, ed. Zinc for Child Health: Proceedings of a Symposium [special issue]. American Journal of Clinical Nutrition 1998; 68: 409S-516S.

3 Brown KH, Wuehler SE, eds. Zinc and Human Health: Results of Recent Trials and Implications for Program Interventions and Research. Ottawa: The Micronutrient Initiative, 2000.

4 Hambidge M, Cousins RJ, Costello RB, eds. Zinc and Health: Current Status and Future Directions [special issue]. Journal of Nutrition 2000; 130: 1341S-519S.

5 Institute of Medicine, Food and Nutrition Board. Dietary Reference Intakes for Vitamin A, Vitamin K, Arsenic, Boron, Chromium, Copper, Iodine, Iron, Manganese, Molybdenum, Nickel, Silicon, Vanadium, and Zinc. Washington, DC: National Academy Press, 2001.

6 Mertz W, Morris ER, Smith JC Jr, Udomkesmalee E, Fields M, Levander OA, et al. Trace elements in the elderly: metabolism, requirements, and recommendations for intakes. In: Munro HN, Danford DE, eds. Nutrition, Aging, and the Elderly. New York: Plenum Press, 1989; 205-17.

7 Hambidge KM. Assessing the trace element status of man. Proceedings of the Nutrition Society 1988; 47: 37-44.

8 World Health Organization (WHO). Trace Elements in Human Nutrition and Health. Geneva: WHO, 1996.

9 Briefel RR, Bialostosky K, Kennedy-Stephenson J, McDowell AM, Ervin RB, Wright JD. Zinc intake of the US population: findings from the Third National Health and Nutrition Examination Survey, 1988-1994. Journal of Nutrition 2000; 130: $1367 \mathrm{~S}-73 \mathrm{~S}$.

10 Institute of Medicine, Food and Nutrition Board. Dietary Reference Intakes: Applications in Dietary Assessment. Washington, DC: National Academy Press, 2000.

11 Barr SI, Murphy SP, Poos MI. Interpreting and using the dietary reference intakes in dietary assessment of individuals and groups. Journal of the American Dietetic Association 2002; 102: 780-8.

12 Cousins RJ. Zinc. In: Ziegler EE, Filer LJ, eds. Present Knowledge in Nutrition. Washington, DC: ILSI Press, 1996; 293-306.

13 Wada L, King JC. Trace element nutrition during pregnancy. Clinical Obstetrics and Gynecology 1994; 37: 574-86.

14 Walsh CT, Sandstead HH, Prasad AS, Newberne PM, Fraker PJ. Zinc: health effects and research priorities for the 1990's. Environmental Health Perspectives 1994; 102(Suppl. 2): $5-46$.

15 Lönnerdal B. Dietary factors influencing zinc absorption. Journal of Nutrition 2000; 130: 1378S-83S.

16 Turnlund JR, King JC, Keyes WR, Gong B, Michel MC. A stable isotope study of zinc absorption in young men: effects on phytate and $\alpha$-cellulose. American Journal of Clinical Nutrition 1984; 40: 1071-7.

17 Rossander L, Sandberg AS, Sandström B. The influence of dietary fibre on mineral absorption and utilization. In: Schweizer TF, Edwards CA, eds. Dietary Fibre - A Component of Food. London: Springer-Verlag, 1992; 197-216.

18 Yang Y, Wang G, Pan X. China Food Composition Table 2002. Beijing: Beijing Medical University Publishing House, 2002; 343pp.

19 Ma G, Jin Y, Piao J, Kok F, Bonnema G, Jacobsen E. Phytate, calcium, iron, and zinc contents and their molar ratios in foods commonly consumed in China. Journal of Agricultural and Food Chemistry 2005; 53: 10285-90.

20 Wang L. Report of China National Nutrition and Health Survey 2002 (1): Summary Report. Beijing: People's Medical Publishing House, 2005; 18-45.

21 Harland BF, Oberleas D. Anion-exchange method for determination of phytate in foods: collaborative study. Journal of the Association of Official Analytical Chemists 1986; 69: 667-70. 
22 Gibson RS. Zinc: the missing link in combating micronutrient malnutrition in developing countries. Proceedings of the Nutrition Society 2006; 65: 51-60.

23 Ma G, Cui Z, Li Y, Hu X, Wang J, Yang X. The survey about the use of dietary supplements by Chinese Adults. Acta Nutrimenta Sinica 2006; 28: 8-10.

24 Ervin RB, Kennedy-Stephenson JK. Mineral intakes of elderly adult supplement and non-supplement users in the Third National Health and Nutrition Examination Survey. Journal of Nutrition 2002; 132: 3422-7.

25 Arsenault EJ, Brown HK. Zinc intake of US preschool children exceeds new dietary reference intakes. American Journal of Clinical Nutrition 2003; 78: 1011-7.

26 Bailey AL, Maisey S, Southon S, Wright AJA, Finglas PM, Fulcher RA. Relationships between micronutrient intake and biochemical indicators of nutrient adequacy in a 'free-living' elderly UK population. British Journal of Nutrition 1997; 77: 225-42.

27 Thane CW, Bates CJ, Prentice A. Zinc and vitamin A intake and status in a national sample of British young people aged 4-18 y. European Journal of Clinical Nutrition 2004; 58 $363-75$.

28 Schulze MB, Linseisen J, Krobe A, Boening H. Macronutrient, vitamin, and mineral intakes in the EPIC-Germany cohorts. Annals of Nutrition \& Metabolism 2001; 45: 181-9.

29 Jong de N, Gibson SR, Thomson DC, Ferguson LE, McKenzie EJ, Green JT, et al. Selenium and zinc status are suboptimal in a sample of older New Zealand women in a communitybased study. Journal of Nutrition 2001; 131: 2677-84.

30 Olivares M, Pizarro F, de Pablo S, Araya M, Uauy R. Iron, zinc, and copper: contents in common Chilean foods and daily intakes in Santiago, Chile. Nutrition 2004; 20: $205-12$

31 Ram BS, Mohammad AN, Shanti SR, Sarita B, Zhang G, Zhu S. Current zinc intakes and risk of diabetes and coronary artery disease and factors associated with insulin resistance in rural and urban populations of North India. Journal of the American College of Nutrition 1998; 17: $564-70$.

32 Joung $H$, Nam G, Yoon S, Lee J, Shim JE, Paik HY. Bioavailable zinc intake of Korean adults in relation to the phytate content of Korean foods. Journal of Food Composition and Analysis 2004; 17: 713-24.
33 Oberleas D, Harland BF. Phytate contents of food: effect on dietary zinc bioavailability. Journal of the American Dietetic Association 1981; 79: 433-6.

34 Ma G, Li Y, Jin Y, Zhai F, Kok FJ, Yang X. Phytate intake and molar ratios of phytate to zinc, iron and calcium in the diets of people in China. European Journal of Clinical Nutrition 2006 Aug 23 [Epub ahead of print].

35 Plaami S, Kumpulainen J. Inositol phosphate content of some cereal-based foods. Journal of Food Composition and Analysis $1995 ; \mathbf{8}: 324-35$

36 Carnovale E, Lombardi-Boccia G, Lugaro E. Phytate and zinc content of Italian diets. Human Nutrition: Applied Nutrition 1987; 41A: 180-6.

37 Kwun IS, Kwon CS. Dietary molar ratios of phytate:zinc and millimolar ratios of phytate $\times$ calcium: zinc in South Koreans. Biological Trace Element Research 2000; 75 : $29-41$.

38 Khokhar S, Pushpanjali, Fenwick GR. Phytate content of Indian foods and intakes by vegetarian Indians of Hisar Region, Haryana State. Journal of Agricultural and Food Chemistry 1994; 42: 2440-4.

39 Brown KH, Peerson JM, Rivera J, Allen LH. Effect of supplemental zinc on the growth and serum zinc concentrations of prepubertal children: a meta-analysis of randomized controlled trials. American Journal of Clinical Nutrition 2002; 75: 1062-71

40 Caulfield LE, Zavaleta N, Shankar AH, Merialdi M. Potential contribution of maternal zinc supplementation during pregnancy to maternal and child survival. American Journal of Clinical Nutrition 1998; 68: 499S-508S.

41 Shah D, Sachdev HPS. Zinc deficiency in pregnancy and fetal outcome. Nutrition Reviews 2006; 64: 15-30.

42 Prasad AS. Biochemistry of Zinc. New York: Plenum, 1993; $193-218$.

43 Hotz C, Lowe NM, Araya M, Brown KH. Assessment of the trace element status of individuals and populations: the example of zinc and copper. Journal of Nutrition 2003; 133: $1563 \mathrm{~S}-8 \mathrm{~S}$.

44 Hotz C, Brown KM. Assessment of the risk of zinc deficiency in populations and options for its control. Food and Nutrition Bulletin 2004; 25: S99-199.

45 Yang $\mathrm{X}$, Wang Z, He Y, Yu W, Hu Y, Zhai F. Trends and prevalence of malnutrition among Chinese children under five years. Acta Nutrimenta Sinica 2005; 27: 185-8. 